International Journal of Instruction e-ISSN: 1308-1470 • www.e-iji.net

Article submission code: 20201216212714

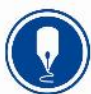

October $2021 \bullet$ Vol.14, No.4

p-ISSN: 1694-609X

pp. $809-824$

Received: $16 / 12 / 2020$

Revision: 27/04/2021
Accepted: $21 / 05 / 2021$

OnlineFirst: 02/09/2021

\title{
Assessing Quality of a Business and Information Technology Alignment Large Enrollment Course
}

\section{Francisco Buitrago-Flórez}

Universidad de los Andes, Bogotá, Colombia, sicks@uniandes.edu.co

Oscar González-Rojas

Universidad de los Andes, Bogotá, Colombia,o-gonzal@uniandes.edu.co

\section{Andrea Herrera}

Universidad de los Andes, Bogotá, Colombia, a-herrer@uniandes.edu.co

\section{Maria Camila Romero}

Universidad de los Andes, Bogotá, Colombia, mc.romero578@uniandes.edu.co

\section{Carola Hernández}

Universidad de los Andes, Bogotá, Colombia, c-hernan@uniandes.edu.co

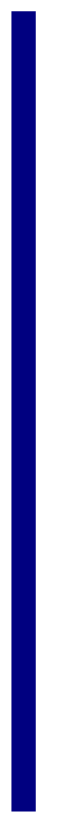

The alignment of Business and Information Technology (BITa) has permeated almost all companies today, mainly due to the benefits that are perceived in their effectiveness and efficiency of their processes, both internal and external. Therefore, higher education must ensure the best settings for equipping IT-related professionals with appropriate BITa knowledge and skills. Consequently, practices related to course quality assessment emerge as critical and helpful since they are capable of generating information to improve teaching and learning processes. This study aims to describe and discuss quality assessment paths for three essential aspects in a large enrollment BITa course: examinations' design, workload, and alignment of activities and concepts to learning objectives. The course includes three main activities to promote the learning process: consultancy project development, examinations, and practical sessions with IT. We developed mixedmethod research to analyze through surveys $(\mathrm{N}=110)$, focus groups (four sessions), workload estimator ( $\mathrm{N}=251)$, and expert consultation (nine experts), the quality of the three aspects of interest. Data indicates that the course curriculum is welldesigned, facilitating the development of BITa knowledge and skills in students. The results also uncover interesting information on helpful pedagogical practices to improve the course curriculum. The proposed approach could be extrapolated to other BITa courses and other courses with large enrollment to understand the students' experiences in relation to the three critical characteristics of learning and teaching practices studied.

Keywords: course quality, BITa, examination' design, workload, course alignment

Citation: Buitrago-Flórez, F., Gonzáles-Rojas, O., Herrera, A., Romero, M. C., \& Hernández, C. (2021). Assessing quality of a business and information technology alignment large enrollment course. International Journal of Instruction, 14(4), 809-824. https://doi.org/10.29333/iji.2021.14446a 


\section{INTRODUCTION}

Information technology (IT) is a crucial aspect of fast growth and adaptation of any business in the $21^{\text {st }}$ century. Such empowering tool has acquired notorious importance as it enables companies to organize their internal and external processes, to communicate with their current and potential customers, as well as to deliver their services to a wide audience (Silvius et al., 2009). Moreover, given the growing position of digitalization and the disruptive trend of social media, data analytics, and cloud computing, companies that fail to incorporate the complex and dynamic field of IT in their business strategy tend to lose competitive advantage (Nikolic et al., 2019). As a result, IT has permeated several economically crucial fields; it has become a topic of interest to executives, consultants, and academics, rising important questions about optimizing the interdependence between business goals and IT services (Luftman \& Kempaiah, 2007). Such interest has led to the emergence of a field known as Business and IT alignment (BITa), which is defined by Silvius, De Waal, and Smit (2009) as "the degree to which IT applications, infrastructure, and organization enable and support the business strategy and processes".

BITa has proven its value throughout literature as it can help organizations in a variety of ways, ranging from maximizing IT investment (Kashanchi \& Toland, 2006), helping to improve the use of IT as a key component of management and productivity (Beimborn et al., 2009), and demonstrating the real value of IT to businesses (Byrd et al., 2006). Furthermore, BITa has become a topic of interest as it has shown a capacity to moderate the association between IT investment and firm performance, proposing that organizations could increase their performance by increasing the alignment between their business and IT, rather than just increasing their IT investment (Charoensuk et al., 2014). Additionally, multiple research studies show that companies are actively engaging in digital transformation, leveraging a wealth of available data to extract added value for improvement (Nikolic et al., 2019).

However, there is a problematic gap between business and IT, which is related to the perceived value of IT investments. The reasons behind this gap lie in organizational structure, IT expertise and knowledge, problematic IT interactions, and cultural differences (Robertson et al., 2018). Therefore, these reasons along with the increased interest and influx of funds in companies concerning BITa strengthens the need for IT managers and IT-professionals to display data-centric reasoning, technical knowledge, dynamic thinking, among other BITa skills, to foster synergy between business and IT within organizations (Ivancic et al., 2019). Hence, higher education institutions must ensure and guarantee a high quality BITa education for students who want to develop their careers in IT-related areas.

On the other hand, the higher education quality is a dynamic, multilevel, and multidimensional concept, which encloses an educational model' contextual settings in the institutions' mission objectives. Likewise, quality can be related to specific standards within a course, program, discipline, institution, or system (UNICEF, 2000). Such variety of branches within the term "quality" can have different and sometimes contradictory meanings, depending on the stakeholders' understanding, their sources, 
and the historical period in the development of higher education (UNICEF, 2007). Also, assessment processes arise when necessary to validate an instance of a curricular design's scope and relevance. Therefore, quantitative and qualitative testing of educational activities and research outcomes is necessary to remain competitive in the higher education field. For universities, ensuring quality in large-enrollment courses is critical because many students must develop multiple essential skills in a single course (Iacob \& Shamal, 2018). At our institution, as well as several tertiary education schools offering IT-related studies worldwide, BITa courses are taken each semester by a wide variety of students from a diverse range of programs, either as a required course or as an elective course.

Previous research has shown the importance of perceiving educational assurance of the quality of teaching and learning as a bottom-up approach (Wilson, 2018). From this perspective, the central purpose of educational assurance is to assist in the educational progress of all students as they navigate through the learning process. Therefore, the most prominent moments of student learning are those orchestrated by the taught curriculum, which is conducive to valuable activities for the development of knowledge and skills in students (Black \& Wilson, 2011). Assessing the design of these activities allows dynamic reflection processes in lecturers, where the most important decisions about student learning could be made and where the greatest impact ultimately occurs (Black \& William, 2018).

Since many students are affected by the course design in a large enrollment setting such as a BITa course, as described by Iacob \& Shamal (2018) three critical aspects of the course regarding the written curriculum (the set of activities and contents planned for a course) and the taught curriculum (the set of activities that actually take place in the development of the course) should be assessed: $i$ ) the design of examinations, $i i)$ the workload and, iii) the alignment of the topics and activities with the development of the desired knowledge and skills. First, examinations' design refers to the extent to which exams effectively evaluate knowledge and skills rather than lower order thinking skills (i.e., memory) (Villarroel et al., 2019). Second, the workload is defined as the design of activities in perfect balance with the available time of a course, which promotes deep and meaningful learning, and fosters the understanding of concepts, the development of skills, and a holistic vision of the course (Soule et al., 2017). Third, the alignment of activities and concepts with learning objectives denotes a process by which the carefully designed curriculum is externally evaluated by experts to determine whether students' experiences are fully encompassed with the course objectives (Rosenbluth et al., 2016). Unfortunately, academic research on the evaluation of these course components in large enrollment courses is almost non-existent in literature. However, by assuring these aspects, coordinators of large enrollment courses can ensure quality in the teaching and learning processes, safeguarding a scenario in which multiple lecturers and students interact each semester.

Given the importance of BITa in the formation of $21^{\text {st }}$ century students and the relevance of quality assessment in higher education, the purpose of this study is to report, as a first, the consolidated quality assessment experiences in a large enrollment BITa course in relation to the three aspects of course assessment previously described. 


\section{Context: Structure and components of the BITa course}

At the School of Engineering in the Universidad de Los Andes, Bogotá - Colombia, the BITa course is denominated as IT in Organizations. It is a 16-week course that involves three hours of synchronous class and six hours of autonomous work per week. Although the course is part of the Computing and Systems Engineering curriculum (students of the program take this course in 4th semester as part of the training in information systems fundamentals), it is also an elective course open to any student of the institution as an opportunity to expand BITa knowledge. For this reason, the course is taken by a large number of students each semester from different undergraduate programs (430 students approximately), especially students from the school of engineering. The students are divided into different class sections, with no more than 25 students per class. The course has an academic writing component, aiming to improve analytical, reflective, argumentative, and critical thinking around the concepts of BITa.

Our BITa course presents the different forms that an organization might display (company, social group, formal or informal organization, etc.), continually emphasizing on IT as a fundamental element to articulate the organization and its environment to achieve its goals. The course's methodology is based on the analysis of different case studies encompassing the three main themes seen in the course. These themes include: i) organizations and their environment, in which students learn about the external forces that affect the ability to acquire and use resources to create value, motivation models, and business models; $i$ ) organizations and their operation, a module in which students interact with the company's value chain and business process modeling using the Business Process Model and Notation (BPMN); and iii) IT and its interaction with the organization's processes, in which students explore how IT can not only support but also reshape business processes. The case studies are reinforced by a set of practical sessions that seek to contextualize the student with some of the main IT tools used in organizations. Furthermore, the final course grade ranges from 1.50 to 5.00, weighted based on three examinations, two group reports and two writing essays based on a consultancy project development, and four practical sessions with IT methods and tools.

To clarify the course structure, we consider necessary to mention the learning objectives and briefly describe the activities that are carried out each semester in the BITa course. First of all, the following are the learning objectives of the course:

Table 1

The learning objectives of the course

ID Objectives of Learning

\begin{tabular}{ll}
\hline O1 & $\begin{array}{l}\text { To understand and build models to describe an organization in terms of its internal characteristics } \\
\text { (business model, culture, strategy, operation) and its interaction with the environment. }\end{array}$ \\
\hline O2 & To develop written and oral skills to justify IT decisions. \\
\hline O3 & $\begin{array}{l}\text { To describe an organization's operation in terms of macro-processes, its value chain, processes and } \\
\text { activities using standards and methodologies. }\end{array}$ \\
\hline O4 & To have knowledge about the IT that supports the organization's processes. \\
\hline O5 & To understand the type of decisions to must be made to establish appropriate IT in a business. \\
\hline
\end{tabular}

Secondly, the following activities are executed in the course to accomplish the objectives mentioned above: 
1. Consultancy project development. A case study is built each semester to recreate a real organization into a fictitious one (for anonymity purposes), which is then defined as the main course project. Multiple media resources (website, videos, documents) are published with information about the organization: strategy, processes, services, interviews, PQRS, etc. Students assume the role of consultants, and they must write texts that discuss the current state and the transformation required for the organization to achieve its desired state. The following activities are defined around this project:

- Group project report I. It is an analysis stage in which groups of consultants use multiple models to characterize the company, analyze the organizational environment, build the motivation model, and build the business model. Then, groups of consultants communicate the main conclusions of this analysis.

- Group project report II. Groups of consultants analyze in detail one of the two given problems/opportunities to determine the organization's transformation direction. This analysis involves identifying the organization's main activities (value chain), modeling the business process that is involved with the selected problem, identifying the issues with the current process, and analyzing the benefits and opportunities of using a specific IT to tackle them.

- Individual essay I. Students assume the role of Project Managers to convince the organization of the sources of competitive advantage over a real-life competitor and how to leverage them to achieve the expected transformation. This essay consists of three parts (deliverables) to enable an iterative argumentation process: a text plan, an initial version, and a final and improved version.

- Individual essay II. Students characterize one of the most critical problems the organization faces and analyze the potential of different IT to tackle it. This essay has two parts (deliverables) to argue the transformation required with IT.

2. Examinations. Three examinations are performed to assess students individually in the acquisition of the expected skills. For this purpose, a real and innovative company is selected, and a brief description of its transformation needs is published. Students investigate the company's specific elements and prepare small challenges to be developed in short periods of time (60 minutes), all focused on the role that IT can have in meeting those needs.

3. Practical sessions with IT. Four practical sessions are deployed in which students assume the role of analysts and decision makers to use IT for business needs. Scenarios related to process modeling, information analysis through the use of Enterprise Information Systems, and business intelligence are developed.

\section{METHOD}

\section{Data gathering and processing}

Educational phenomena are particularly complex and often require robust methods to understand them in depth (Green et al., 2015). Therefore in this research study, evaluation for education research is understood as the systematic collection of information about the activities, features, and outcomes associated with analyzing the 
quality of a course (Bamberger, 2012). Hence, we decided to assure the relevance and quality of course examinations, workload, and alignment of topics and activities with the learning objectives, through a mixed method design. Figure 1 summarizes the quantitative and qualitative techniques defined for analyzing the quality of the three types of assessments defined for the massive BITa course. These assessments and techniques are presented in the following sections.

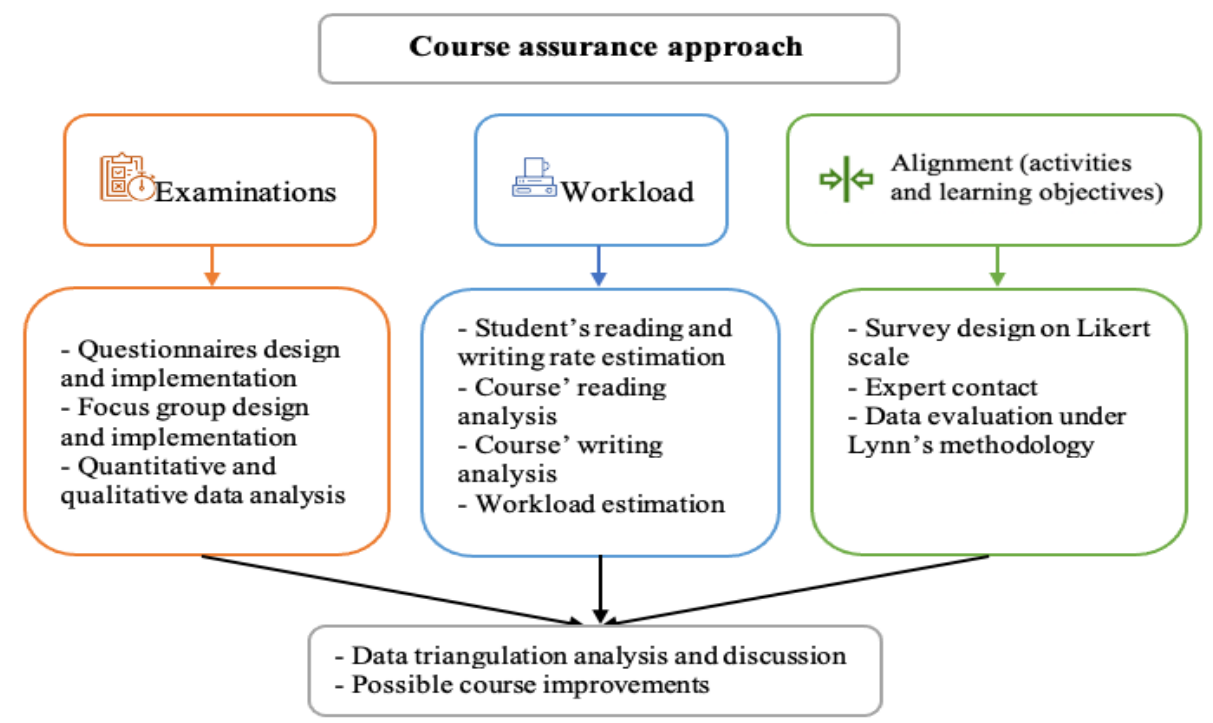

Figure 1

Schematical representation of the course assurance approach

This approach was chosen to maximize the power of the information collected and to strengthen the overall evaluation. Taking into account Tashakkori and Teddle (2002) descriptions of mixed methods, the research herein presented simultaneously adopts a quantitative and qualitative approach to shed light on information on the multiple components addressed in assessing the quality of the BITa course. As such, our research design was deployed by collecting information with open-ended and close-ended approaches, following a program-objective framework in which researchers concurrently use both data streams within an overall objective, thus guiding the integration of multiple phases in a multiphase research project (Creswell, 2009). Moreover, information from each of the instruments was subsequently triangulated to form a meaningful overview of the course examinations, workload, and alignment of topics and activities with the learning objectives, by using the majority strategy for aggregating information while triangulating as established by Patton (1999).

\section{First assessment: Examination assurance}

Since we were interested in determining perceptions, attitudes, and relevance to ensure examination practices in the BITa course, we decide to collect in-deep explanatory 
information through close-ended surveys $(\mathrm{N}=110)$ and focus groups $(4$ sessions of 10 students each) deployed with students. On the one hand, in education research, questionnaires allow researchers to gather information that all those involved in the teaching and learning process are able to report about curricular processes (Xerri, 2017). In order to avoid a possible superficial assessment of a very complex construct, which is the main downside described for questionnaires (Wagner, 2010), the instruments' development was carried out following the guidelines proposed by (Constable, 2014). This methodology states that the creation of questions must be encompassed with a set of hypotheses for their validation. On the other hand, we decided to use the benefits of focus groups given that such a qualitative instrument allowed us to retrieve additional data about the BITa course examinations, generating a synergic conversation among the participants through a logical sequence of questions (Lecanda \& Garrido, 2003). Students were asked about the three BITa course examinations; questions regarded the examination's length, clarity of questions, alignment with learning objectives, and feedback in both instruments. All participants signed informed consent for data gathering, as required for the institution's ethics committee.

\section{Second assessment: Workload assurance}

To assure the course workload, we used the online course workload estimation tool developed by the Center for Teaching Excellence of Rice University (https://cte.rice.edu/workload). This tool takes into account four main criteria to calculate workload. The first is the reading criterion, which includes the number of pages per week to read, the page density, the difficulty of the reading, and the purpose of the reading process in the course. The second one is the writing criterion including pages per semester of writing, the word density per page, the genre and, whether or not it requires drafting. The third and four criteria are the number of exams per semester (taking into account the hours of study per exam) and the hours needed to develop other assignments, respectively. To use the workload estimator successfully, we realized that it was essential to know the estimated reading and writing rate of students enrolled in the BITa course. Therefore, we developed an open-ended questionnaire composed of questions designed to determine the average time students spend reading a 500-word BITa text and the time students spend writing a 500-word BITa essay. The questionnaire was designed and deployed on the Blackboard ${ }^{\circledR}$ platform, which provides the functionality to extract the times students open and submit each of their responses. Once the estimated reading and writing rates were obtained, then we calculated how many pages students had to read and write per semester in the BITa course and then we estimated, through lecturer discussions and surveys, how much time the students required to study for each exam. The questionnaire was voluntarily and anonymously answered by 251 students. Once all the necessary data was collected, the total estimated workload for the BITa course was calculated.

\section{Third assessment: Concepts and activities alignment with learning objectives}

Aiming to ensure the last component of the BITa course related to the alignment of concepts and activities with the learning objectives, we conducted an expert validation of the activities. Hyrkas et al., (2003) show that eight to ten is a number proven to be 
sufficient to obtain a valid estimation. Consequently, ten experts in the BITa field were contacted to respond to a survey describing each course's concepts and activities. The experts were asked to express on scale of 1 to 10 how much they agreed that such concept and activity was relevant to develop a particular BITa learning objective. To evaluate each of the survey questions, we followed Lynn's methodology (Lynn, 1986), which allows researchers to evaluate the proportion of experts who agree with the statement. The methodology establishes that if the average of the answers related to each question is equal or higher than 8.0/10, there is a consensus among experts that a specific set of concepts or activities effectively leads to developing a specific learning objective. A total of nine experts answered the survey.

\section{FINDINGS}

The research design was used to establish the quality of specific aspects of the of a BITa course curriculum. This section summarizes the quantitative and qualitative analyses and discusses the results in separate sub-sections regarding the three aspects of interest: examinations' design, workload, and concepts and activities alignment with learning objectives.

\section{Examinations}

Surveys and focus groups evaluated four criteria regarding course examinations: length, clarity of questions, alignment with learning objectives, and feedback. Additionally, the data gathered for each of the four criteria was classified into two categories to facilitate results presentation. As there are three different examinations that students must encounter throughout the BITa course, we decided to report our results in three different tables, one for each examination, as follows:

Table 2

Data for the four established criteria for examination 1. Percentages are based on the total of students surveyed $(\mathrm{N}=110$ from an approximate population of 430$)$.

\begin{tabular}{lll} 
& Length & Enough: $94 \%$ \\
\cline { 2 - 3 } & & Too long: 6\% \\
\cline { 2 - 3 } Examination 1 & Clarity of questions & Clear: $92 \%$ \\
\cline { 2 - 3 } & Alignment with learning objectives & Not Clear: $8 \%$ \\
\cline { 2 - 3 } & & Aligned: $90 \%$ \\
\cline { 2 - 3 } & Feedback & Not Aligned: $10 \%$ \\
\cline { 2 - 3 } & & Appropriated: $92 \%$ \\
\hline
\end{tabular}


Table 3

Data for the four established criteria for examination 2. Percentages are based on the total of students surveyed $(\mathrm{N}=110)$.

\begin{tabular}{|c|c|c|}
\hline \multirow{8}{*}{ Examination 2} & \multirow[t]{2}{*}{ Length } & Enough: $45 \%$ \\
\hline & & Too long: $55 \%$ \\
\hline & \multirow[t]{2}{*}{ Clarity of questions } & Clear: 89\% \\
\hline & & Not Clear: $11 \%$ \\
\hline & \multirow[t]{2}{*}{ Alignment with learning objectives } & Aligned: $91 \%$ \\
\hline & & Not Aligned: $9 \%$ \\
\hline & \multirow[t]{2}{*}{ Feedback } & Appropriated: $90 \%$ \\
\hline & & Not Appropriated: $10 \%$ \\
\hline
\end{tabular}

Table 4

Data for the four established criteria for examination 3. Percentages are based on the total of students surveyed $(\mathrm{N}=110)$.

\begin{tabular}{lll}
\hline & Length & Enough: $88 \%$ \\
\cline { 2 - 3 } & & Too long: 12\% \\
\cline { 2 - 3 } Examination 3 3 & Clarity of questions & Not $\%$ \\
\cline { 2 - 3 } & Alignment with learning objectives & Aligned: $87 \%$ \\
\cline { 2 - 3 } & & Not Aligned: $13 \%$ \\
\cline { 2 - 3 } & Feedback & Appropriated: 89\% \\
\cline { 2 - 3 } & & Not Appropriated: 11\% \\
\hline
\end{tabular}

In general, students agreed that the time provided for examinations 1 and 3 was enough to solve all the questions proposed. Regarding examination 2, however, most students expressed that the test was significantly longer for the time provided. Such a claim was discussed with the BITa lecturers, who reflected on the exam and agreed that it might be too long for students. Moreover, the small amount of variance showed that most students agreed that the three examinations' design was good enough to provide clarity of their questions, alignment with the learning objectives and feedback. For instance, in a focus group, three students stated:

"The statements are clear, so there is no need to ask additional questions during the exams."

"I think that the examinations assess exactly the objectives of the course."

"I can say that feedback is always provided at the agreed upon times."

These results are the product of several reflections by the lecturers of the BITa course on the examinations, which have resulted in very robust, relevant, and well-designed tests that effectively measure knowledge and skills in the BITa. A specific characteristic of this large enrollment course, which allows for organization and reflection across class sections throughout the semesters, is that a lecturer is responsible for assuming the role of coordinator of the BITa. This role carries out academic and curricular actions to facilitate the teaching and learning processes and promote meetings to discuss the BITa course's relevant issues. Furthermore, training sessions are frequently held for the BITa 
lecturers aiming to continuously reflect on pedagogical processes and the state of the art of BITa concepts and practices.

Another exciting result we obtained is related to oral examinations. Some lecturers in the BITa course conduct oral examinations instead of written examinations to assess students' performance. It is an optional decision that lecturers are free to implement. Regarding this topic, several students expressed that they feel more confident in taking oral evaluations, as this process promotes a more reflective understanding of BITa concepts and practices. Such claims are based on the fact that students feel they need to be better prepared to talk to a lecturer than to write down answers on a piece of paper; otherwise, students could have moments of confusion or be involved in a very embarrassing situation on oral examinations. As two students recounted in a focus group:

"It is not just about writing whatever you can write, even if it's wrong. In oral evaluations, you have to understand the concepts to explain them to the lecturer."

"I think that you arrive at the oral evaluation more prepared since to express yourself, you have to understand the concepts in depth."

\section{Workload}

In order to successfully calculate the workload outside the classroom using the workload estimator designed by Rice University, we decided to implement a test to obtain data on the average reading and writing rate students have when they are enrolled in the BITa course. The test was taken voluntarily by 251 students in the second semester of 2019 and the first semester of 2020. On average, we found that students spend one hour successfully reading 12 pages of a BITa reading and spend 1.22 hours successfully writing one page (500 words) of a BITa essay.

In addition, we developed a careful analysis of the reading material and the writing activities that students must develop in the BITa course. In the case of reading material, we found that students must read an average of 25 pages per week throughout the semester, each page with an average density of approximately 450 words. All the material is intended to help students understand concepts, as the reading material plays a supporting role in the activities in the BITa classes. As for the writing activities, we found that by adding both, group reports and written essays, students must write an average of 8.5 pages per semester. Additionally, we determined that all writing deliverables are argumentative texts with minimal initial drafting.

Once a student's reading and writing rate were established, we calculated the BITa course workload through the course workload estimator. The online tool also requested how many hours of study students should spend per exam, and we concluded that students should spend at least 6 hours (six times the length of a single examination) to prepare themselves for each of the three course evaluations. No other assignments were included in the analysis since all additional assignments are developed in class, such as workshops and hands on. We ended up with an estimated workload of 3.39 hours per week of out-of-class work, as seen in Figure 2. This result is well below the six stated hours of out-of-class work that students are required to dedicate when enrolling in the 
BITa course, revealing that the established curriculum is designed to avoid students' cognitive workload.

Course Workload Estimator
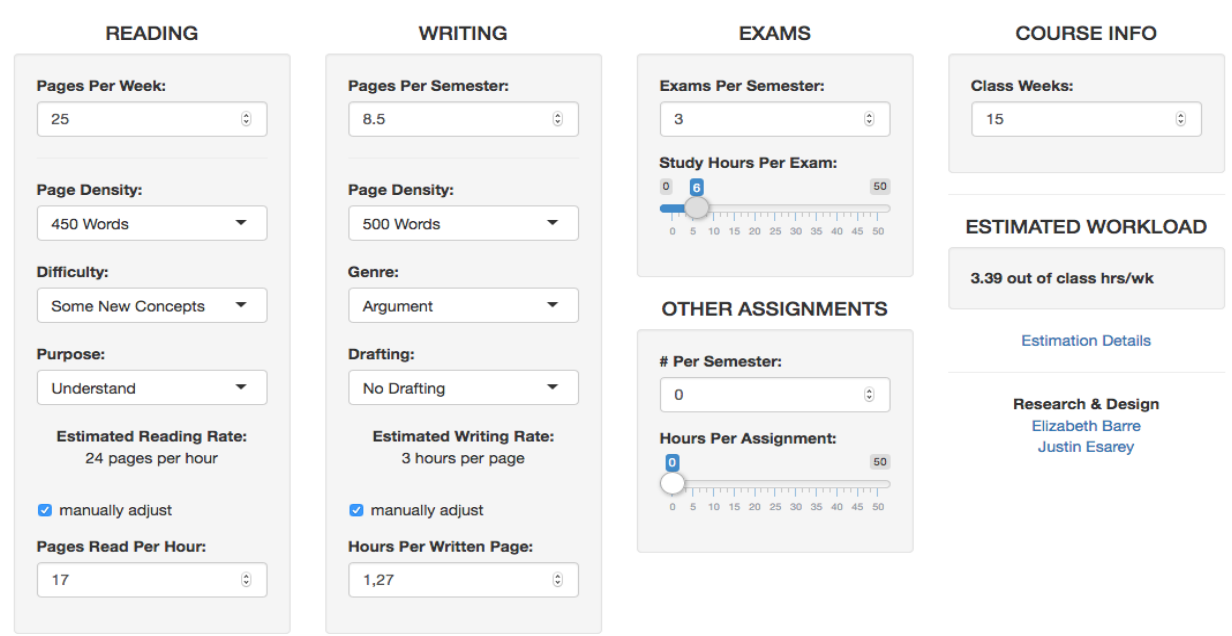

Figure 2

The estimated workload of the BITa course. Highlighted in red is the result of the 3.39 hours out-of-class workload per week. Online tool available at https://cte.rice.edu/workload

\section{Concepts and activities alignment with objectives of learning}

The alignment of curricular activities and concepts is one of the most important axes for the courses' quality assurance since it can be considered the core of the curricular design. To achieve such an endeavor, we developed a 1 to 10 scale survey describing the relationship between the activities and concepts that students experience throughout the semester with the learning objectives of the BITa course; the results are summarized in Table 5. The survey was answered by nine external experts in the field of BITa, who were in charge of evaluating our BITa course's curricular design alignment. Additionally, the experts had the opportunity to comment openly and extensively on the activities and concepts described.

Results show that the activities and concepts addressed throughout the course are essentially in line with the established learning objectives. In more detail, the group project reports, and some individual essay parts show a score below 8.50, mainly derived from the lack of clarity of the activities related to oral communication. Most experts agree that oral presentations, oral exams, or other pedagogical tools must be clearly implemented to meet the course's third learning objective successfully. We have examined and reflected on this result and agreed that some additional activities could favor developing students' oral communication skills. Furthermore, all the experts perceived the three examinations as adequate and well designed for the learning objectives; this result converges with the participating students' opinion. 
Table 5

Results obtained from the expert evaluation

\begin{tabular}{lll}
\hline Activity / Concept & Objectives of Learning & Average score (1/10) \\
\hline Group project report I & $\mathrm{O} 1, \mathrm{O} 2, \mathrm{O} 3$ & 8.40 \\
\hline Group project report II & $\mathrm{O} 3, \mathrm{O} 4, \mathrm{O} 5, \mathrm{O} 6$ & 8.44 \\
\hline Individual essay I part I & $\mathrm{O} 1, \mathrm{O} 2, \mathrm{O} 3$ & 8.41 \\
\hline Individual essay I part II & $\mathrm{O} 1, \mathrm{O} 2, \mathrm{O} 3$ & 8.74 \\
\hline Individual essay I part III & $\mathrm{O} 1, \mathrm{O} 2, \mathrm{O} 3$ & 9.33 \\
\hline Individual essay II part I & $\mathrm{O} 3, \mathrm{O} 5, \mathrm{O} 6$ & 8.37 \\
\hline Individual essay II part II & $\mathrm{O} 3, \mathrm{O} 5, \mathrm{O} 6$ & 8.81 \\
\hline Examination I & $\mathrm{O} 1, \mathrm{O} 2$ & 9.44 \\
\hline Examination II & $\mathrm{O} 4$ & 9.55 \\
\hline Examination III & $\mathrm{O} 5, \mathrm{O} 6$ & 8.94 \\
\hline Practical sessions & $\mathrm{O} 4, \mathrm{O} 5$ & 8.63 \\
\hline
\end{tabular}

The survey's open comments section provided interesting information; three experts talked about using the Business Process Model and Notation (BPMN). BPMN is used throughout our BITa course since it is one of the most widely used graphical representations for business process modeling. However, the experts mentioned that it could be interesting and useful to address other notations to describe a business process, and thus, students could have a more general view of it. This is an interesting point of discussion since other perspectives could enhance a broader view of this part of the course in students but could lead to confusion. We will take these data to start some discussions among lecturers, looking for the best approach to work on this issue.

\section{DISCUSSION}

The BITa has become a concerning research topic in companies and higher education institutions, considering the increasingly rapid pace at which information technologies permeate almost any business model, making it work effectively and efficiently (Ivancic et al., 2019). This importance BITa has to society has prompted multiple courses in engineering and other educational fields, which seek to equip future professionals with the necessary skills to meet the challenges, either as employees or as entrepreneurs. However, this is not an easy task since the understanding of BITa relies on high-level skills such as data-centric reasoning, technical skills, and dynamic thinking, which are somehow difficult to develop (Nikolic et al., 2019). Therefore, BITa courses in higher education programs must be designed and assessed to promote the development of appropriate knowledge and skills in order to successfully meet the requirements of the professional market. Such an endeavor would unequivocally improve companies' IT decisions, increasing their performance, and profit (Charoensuk et al., 2014).

The quality of education in universities should be a matter of great concern to all stakeholders. Higher education institutions must demonstrate excellence in all the steps considered in the teaching and learning processes, from curriculum design to the taught curriculum, as well as from lecturer training to lecturer evaluation (Black \& William, 2018). Therefore, the quality of teaching and learning can only be assured by evaluating all its components, including course-specific characteristics such as examination's 
design, workload, and alignment of activities and learning objectives (Iacob \& Shamal, 2018). Unfortunately, as stated before these course components are often not assessed in IT-related courses, leaving potential concerns unanswered. Moreover, the three components subject of research in this study become more worrisome in large enrollment courses because even a minor inaccuracy in the relevance of the assessments, an excessive workload, or a misalignment of activities with learning objectives, could result in undesirable outcomes affecting a massive number of students in their learning process.

The triangulation of data associated with the assessment axes in our BITa course indicates a well-designed course curriculum, facilitating the development of BITa knowledge and skills in students. These results are valuable, as we obtained information about the current status of our course. Initially, the BITa teachers determined that this status was satisfactory but was seriously clouded by doubts regarding the success of examinations, the workload, and the alignment of activities and concepts with the learning objectives. The assessment of these characteristics of the BITa course provides clear information to the lecturers that generate tranquility since the results were positive in all the evaluated characteristics. Therefore, our teaching practice has become more secured as we are confident that hundreds of IT-related students are receiving a welldesigned BITa curriculum course each semester. Moreover, this type of assessment brings to light information about the pedagogical practices that the lecturer includes in their teaching methodologies. For instance, we did not expect favorable oral examinations results, as this methodology might seem intimidating to students; nevertheless, further research is needed to decide whether this evaluation method is the most appropriate for BITa evaluations.

Overall, this research study consolidates and articulates key assessment strategies to determine whether a course curriculum's particular characteristics are working as desired. Developing assessment strategies that actively include students' voices generate a clear idea of what students are experiencing (taught curriculum), which in many cases could be different from what is planned by lecturers (written curriculum) and produces a misalignment between the objectives of learning and the actual learning experiences students receive (Wilson, 2018). Therefore, the proposed approach could be extrapolated to multiple courses to understand students' experiences in terms of examinations, workload, and alignment of learning objectives with activities and concepts (see Figure 2 in the method section). As such, this research study can be visualized as a novel base ground reference for the implementation of a bottom-up approach to assure key taught curriculum activities, which ultimately leads to the important process of ensuring educational quality of large enrollment courses through professor's reflections and informed decision-making procedures (Black \& William, 2018).

Finally, we encourage BITa lecturers and, in general, IT- lecturers to reflect on these characteristics of their courses in order to generate and continuously improve the learning environment for students. We strongly believe that by assessing and improving what students can learn in their courses, IT professionals can perform better in their field 
once they graduate. A better prepared IT workforce will lead to improved business and industry performance, generating countless benefits not only for employers and employees but for multiple sectors of our society.

\section{CONCLUSIONS}

Business and Information Technologies alignment (BITa) has become a great interest field, given its growing importance to companies' performance. IT-related professionals who may be involved in the BITa field must have solid basic training so that they can demonstrate, as needed, the BITa knowledge and skills. Hence, BITa courses in higher education, whether mandatory or elective for IT-related programs, must have a welldesigned curriculum and good practices for quality course assessment. In the study herein presented, we developed some key assessment pathways to understand the state of assessment relevance, workload, and alignment of activities and concepts with learning objectives in a large enrolment BITa course. Such assessment pathways allowed us to critically understand what students are able to experience concerning these three course characteristics while providing us with inspiring information that allows us to improve the learning and teaching processes in our BITa course. Thanks to these assessment practices and the data gathered we are convinced that our BITa course provides a well-suited learning scenario, equipping IT-related students with valuable knowledge and skills for BITa field's challenges.

We strongly believe that the results described and discussed in this paper offer exciting alternatives and practices for quality assessment for BITa courses and any large enrollment course belonging to any school or faculty. Therefore, we kindly invite professors to reflect on the quality of education and course assessment and explore the multi-component assessment approach described here and develop and implement assessment strategies to increase students' benefits from enrolling in their course. Following these reflections, the overall quality of higher education could be influenced by professionals' better development.

This study has focused on a specific course of our institution. To build a more comprehensive picture of the power of our educational innovation, the methodology should be implemented in other large enrollment courses not only related to BITa and IT, but to a wide range of disciplines and audiences. Data from different courses could improve the analysis of the scope and limitations of our proposal and could provide a more general framework for the successful assessment of the three course characteristics that are subject of this research.

\section{ACKNOWLEDGMENTS}

We would like to thank all students, lecturers, and experts involved in the process to participate and offer exciting insights into the BITa course. We would also like to thank the Systems and Computing Engineering Department at the School of Engineering of the Universidad de Los Andes for facilitating the resources for the development of this study. 


\section{REFERENCES}

Bamberger, M. (2012). Evaluation for Equitable Development Results (UNICEF Eva). http://www.clear-la.cide.edu/sites/default/files/Evaluation_for_equitable results_web.pdf

Beimborn, F., Schlosser, F., \& Weitzel, T. (2009). Proposing a Theoretical Model for IT Governance and IT Business alignment. Proceedings of the 42nd Hawaii International Conference on System Sciences (HICSS 2009), Waikoloa, Hawaii.

Black, P., \& William, D. (2018). Classroom assessment and pedagogy. Assessment in Education: Principles, Policy \& Practice, 25(6), 551-575. https://doi.org/10.1080/0969594X.2018.1441807

Black, P., \& Wilson, M. (2011). Road Maps for Learning: A Guide to the Navigation of Learning Progressions. Measurement: Interdisciplinary Research and Perspectives, 9(1), 71-123.

Byrd, T., Lewis, B., \& Bryan, R. (2006). The Leveraging Influence of Strategic alignment on IT Investment: An Empirical Examinations. Information \& Managemen, 43(3), 308-321. https://doi.org/10.1016/j.im.2005.07.002

Charoensuk, S., Winai, W., \& Khang, D. (2014). Business-IT Alignment: A Practical Research Approach. Journal of High Techonolgy Managment Research, 25(1), 132147. https://doi.org/10.1016/j.hitech.2014.07.002

Constable, G. (2014). Talking to Humans: Success starts with understanding your customers (Amazon Digital Services (ed.)).

Creswell, J. (2009). Research Design: Qualitative, Quantitative, and Mixed Methods Approaches. 3rd ed. Thousands Oaks, CA:Sage.

Green, J., Bouce, A., \& Ahn, J. (2015). A Values-Engaged, Educative Approach for Evaluating Education Programs: A Guidebook for Practice. University of Illinois publications. United States.

Iacob, C., \& Shamal, F. (2018). Redesigning an Undergraduate Software Engineering Course for a Large Cohort. ICSE'18, May 2018, Gothenburg Sweden, 1-9.

Ivancic, L., Vuksic, V., \& Spremic, M. (2019). Mastering the Digital Transformation Process: Business Practices and Lessons Learned. Technology Innovation Management Review, 9(2), 36-50. https://doi.org/10.22215/timreview/1217

Kashanchi, R., \& Toland, J. (2006). Can ITIL Contribute to IT/Business alignment? An Initial Investigation. Wirtschaftsinformatic, 48(5), 340-348.

Lecanda, R., \& Garrido, C. (2003). Introducción a la metodología de investigación cualitativa. Revista de Psicodidáctica Bilbao, 14(1), 5-40. http://www.redalyc.org/articulo.oa?id=17501402

Luftman, J., \& Kempaiah, R. (2007). An Update on Business-IT alignment: "A line" has been Drawn. MIS Quarterly Executive, 6(3), 165-177. https://aisel.aisnet.org/misqe/vol6/iss3/5/ 
Lynn, M. (1986). Determination and Quantification of Content Validity. Nursing Research, 35(1), 382-385. https://doi.org/10.1097/00006199-198611000-00017

Nikolic, B., Ivancic, L., \& Glavan, L. (2019). Developing Business - IT Alignment Skills Through Data Management: Higher Education Example. 49th International Scientific Conference on Economic and Social Development Development - "Building Resilient Society, ” 4-13.

Patton, M. (1999). Enhancing the quality and credibility of qualitative analysis. Health Ser Res, 34, 1189-1208.

Robertson, E., Peko, G., \& Sundaram, D. (2018). Enterprise Architecture Maturity: A Crucial Link in Business and IT Alignment. PACIS 2018 Proceedings. 308.

Rosenbluth, A., Cruzat-Mandich, C., \& Urgate, M. (2016). Methodology to Validate a Competencies Assessment Tool for Psychology Students. Universitas Psychologica, 16(1), 303-314. https://doi.org/10.11144/Javeriana.upsy15-1.ppmp

Silvius, A., De Waal, B., \& Smit, J. (2009). Business and IT Alignment Answers and Remaining Questions. PACIS 2009 - 13th Pacific Asia Conference on Information Systems: IT Services in a Global Environment.

Soulé, J., Førland, O., \& T., D. (2017). Sense and Sensibility in Workload Calculation. MNT Conference, 30-31 March 2017, Oslo.

Tashakkori, A., \& Teddle, C. (2002). Handbook of mixed methods in social and behavioral research. Thousand Oaks, CA: Sage.

UNICEF. (2007). Quality Assurance and Accreditation: A Glossary of Basic Terms and Definitions.

UNICEF. (2000). Defining Quality in Education. Meeting of The International Working Group on Education Florence, Italy, 1-44.

Villarroel, V., Boud, D., Bloxham, S., Bruna, D., \& Bruna, C. (2019). Using Principles of Authentic Assessment to Redesign Written Examinations and Tests. Innovations in Education and Teaching International, 1-13. https://doi.org/10.1080/14703297.2018.1564882

Wagner, E. (2010). Survey research. In Continuum companion to research in applied linguistics (pp. 22-38). Continuum.

Wilson, M. (2018). Making Measurement Important for Education: The Crucial Role of Classroom Assessment. Educational Measurement: Issues and Practice, 37(1), 5-20.

Xerri, D. (2017). Using Questionnaires in Teacher Research. The Clearing House: A Journal of Educational Strategies, Issues and Ideas, 90(3), 65-69. https://doi.org/10.1080/00098655.2016.1268033 